Trinity University

Digital Commons @ Trinity

Physics and Astronomy Faculty Research

Physics and Astronomy Department

1998

\title{
Magnetospheric Response Times Following Southward IMF Turnings
}

Niescja E. Turner

Trinity University, nturner1@trinity.edu

D N. Baker

T I. Pulkkinen

H J. Singer

F Mozer

Follow this and additional works at: https://digitalcommons.trinity.edu/physics_faculty

Part of the Astrophysics and Astronomy Commons

\section{Repository Citation}

Turner, N. E., Baker, D. N., Pulkkinen, T. I., Singer, H. J., \& Mozer, F. (1998). Magnetospheric response times following southward IMF turnings. In S. Kokubun \& Y. Kamide (Ed.), Substorms-4: International Conference on Substorms-4, Lake Hamana, Japan, March 9-13, 1998 (pp. 711-714). Terra Scientific.

This Contribution to Book is brought to you for free and open access by the Physics and Astronomy Department at Digital Commons @ Trinity. It has been accepted for inclusion in Physics and Astronomy Faculty Research by an authorized administrator of Digital Commons @ Trinity. For more information, please contact jcostanz@trinity.edu. 


\title{
MAGNETOSPHERIC RESPONSE TIMES FOLLOWING SOUTHWARD IMF TURNINGS
}

\author{
N. E. Turner and D. N. Baker \\ LASP, University of Colorado \\ Boulder, $\mathrm{CO}$ \\ T. I. Pulkkinen \\ Finnish Meteorological Institute \\ Helsinki, Finland \\ H. J. Singer \\ NOAA SEC, Boulder, CO \\ F. Mozer \\ U. California, Berkeley, CA
}

\begin{abstract}
We analyze the response times of various regions of the magnetosphere-ionosphere system to sudden southward turnings of the IMF. Our data set consists of 26 events during which the IMF $B_{Z}$ component was observed by WIND to change from a steady northward field to a southward field, which subsequently led to a substorm. The magnetospheric response to such IMF southward turnings is examined using data from the POLAR EFI experiment, the GOES 9 magnetometer, and ground magnetometers. The POLAR/EFI was used to investigate changes in the polar cap electric field which occurred in response to the changing interplanetary electric field, and these results are compared with response timings derived from high-latitude ground magnetometers. POLAR/EFI data show responses in the polar cap about 15 minutes after the arrival of the IMF change at the magnetopause. Auroral zone magnetograms and geosynchronous spacecraft measurements are utilized to evaluate the response timing within the closed field line region. In one event examined in detail, the start of a substorm growth phase was observed by GOES 9 in the midnight sector of geosynchronous orbit about two minutes before POLAR observed a response in the polar cap. Using superposed epoch analysis, we calculate typical response times in the polar cap, in the nightside plasma sheet, and in the ionosphere in order to discuss the various suggested mechanisms for information propagation from the subsolar magnetopause into the magnetosphere. We find that for the set of ten events for which GOES 9 and the CANOPUS array are in the midnight sector, the field at geosynchronous as measured by GOES responds at or before the time of response in the polar cap as measured by POLAR, suggesting different methods of information propagation.
\end{abstract}

\section{Introduction}

Southward turnings of the IMF are known to initiate the transfer of energy from the solar wind into the magnetosphere that culminates in substorms [Baker at al., 1996, and references therein]. While the entire magnetosphere reacts to these events, the methods of information propagation from the reconnection site throughout the magnetosphere are not wellestablished. This study uses satellite and ground-based monitors to investigate the propagation of information into the polar cap and geosynchronous orbit regions, as well as the auroral ionosphere.

Much work has been done on the response of the polar ionosphere to changes in the IMF. For example, Cumnock et al. [1992] investigated the polar cap response to a $B_{Y}$ rotation in one particular event and Hairston and Heelis [1995] analyzed a single three-day period during which there were five IMF $B_{Z}$ southward turnings. Hairston and Heelis used DMSP data to obtain polar cap convection patterns and determined that the response time of the polar ionosphere to the IMF reversals was about 17 to 25 minutes. This lag was interpreted as an inertial response time of the ionosphere to IMF changes.

Work by Ridley et al. [1997] focused on the ionospheric response to southward IMF turnings for six events. Ridley et al. used the Assimilative Mapping of Ionospheric Electrodynamics (AMIE) technique to investigate polar cap convection patterns in response to IMF $B_{Z}$ reversals. They determined that the ionospheric convection changes grew linearly with time and were linearly proportional to the change observed in the IMF $B_{Y}$ or $B_{Z}$ components. Further work by Ridley et al. [1998] used the same technique to investigate 65 events for a statistical study. They found that reconfiguration of the polar convection patterns started about $8.4 \pm 8.2$ minutes after the solar wind change reached the magnetopause and continued to reconfigure for about 13 minutes until it reached a steady state.

Turner et al. [1998] showed that the mean of the polar cap electric field at altitudes of $5-9 R_{E}$ typically changes within 15 minutes of an IMF southward turning. They also presented a single event where the GOES 9 magnetometer, near midnight local time, responded to the IMF before the polar cap response was measured. 
In this study, we investigate the absolute and relative timings of responses seen in the polar cap and geosynchronous orbit and on the ground after sharp IMF changes to determine the response times of the various regions to changing solar wind conditions. In particular, we look at 26 events during which the IMF $B_{Z}$ component changed from northward to southward (corresponding to interplanetary $E_{Y}$ changing from negative to positive) after at least an hour of steady, northward IMF conditions. We also conduct a superposed epoch analysis of the electric field measured by POLAR as well as the magnetic fields measured by GOES 9 and the CANOPUS magnetometer array for all ten events for which GOES 9 was near midnight in its geosynchronous orbit.

\section{Instrumentation}

Several spacecraft, both inside and outside the magnetosphere, were used in this study. The WIND spacecraft was used to provide magnetic field and solar wind data which were then used to identify events. Inside the magnetosphere were GOES 9 and POLAR. GOES 9 is in a geosynchronous orbit and was used for magnetic field measurements, both to identify substorm timings and to obtain information about the inner magnetosphere dynamics and response. The CANOPUS array of ground-based magnetometers was used to provide information about the timing of the responses observed on the ground.

The POLAR spacecraft is in a highly elliptical orbit which reaches apogee at about $9 R_{E}$ over the north pole and perigee at $1.8 R_{E}$ over the south pole. The EFI instrument on POLAR was used to obtain electric field data in the northern polar cap. The threedimensional field measurements were taken by three pairs of booms: two wire boom pairs in the spin plane of the spacecraft and one rigid stacer pair on the spin axis. The sensors on the spin-plane booms are about 130 meters apart, while the spin-axis sensors are only 13.8 meters apart. This difference is because those in the spin plane can be held away from the spacecraft centrifugally, while the on-axis booms must be rigid and are therefore shorter [Harvey et al., 1995]. Because the on-axis booms are closer to the spacecraft, they are more sensitive to the spacecraft potential and the plasma environment around the satellite. To avoid contamination difficulties with the shorter booms, only the spin-plane measurements are used in this study.

\section{Observations and Data Analysis}

\subsection{Event Selection}

Sudden changes in the IMF $B_{Z}$ from northward to southward which followed an hour or more of relatively stable IMF conditions were examined. These event identifications were made using data from June, 1996 through April, 1997 from the WIND MFI magnetometer. Selections were further narrowed by choosing only those events for which POLAR was in the northern po-
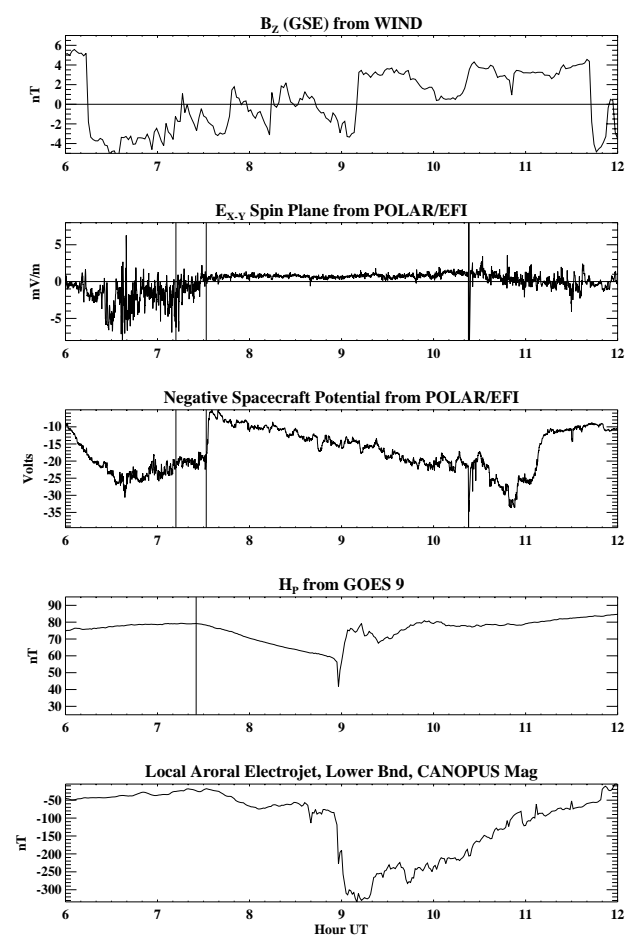

Figure 1: Data from the June 17, 1996 event

lar cap. The northern cap is preferable to the southern cap because POLAR apogee is over the northern cap. Thus, the spacecraft spends a much longer time in the northern than the southern polar region, making it easier to separate temporal from spatial effects. The events were then examined to find times when GOES 9 and the CANOPUS chain were in the midnight sector of geosynchronous orbit, leaving ten of the events used for the electric field superposition that could be studied using GOES 9 and the CANOPUS magnetometer array as well.

\subsection{June 17, 1996 Event}

Turner et al. [1998] studied an event which occurred on June 17, 1996 which showed a response at geosynchronous orbit before the response measured by POLAR. In this event, the arrival time of the discontinuity at the magnetopause was estimated to be 0712 UT. The POLAR spacecraft was located in the polar cap, almost at apogee, at the predicted arrival time of the discontinuity at Earth. At 0732 UT, the E-field (Figure 1, panel 2) underwent a sudden state change. The measured E-field was observed to change from a widely varying and rapidly fluctuating character to relatively smooth, steady values in addition to a sudden change in the mean of the field.

At 0725 UT, GOES 9, which was located near local midnight in geosynchronous orbit, observed Hp (Figure 1, panel 4), the magnetic field component parallel to the Earth's spin axis, to start decreasing. This decrease indicated field line stretching in the tail, and was the start of the substorm growth phase [e.g., Baker et al., 1996 and Singer and Wolf, 1992]. Note that this 

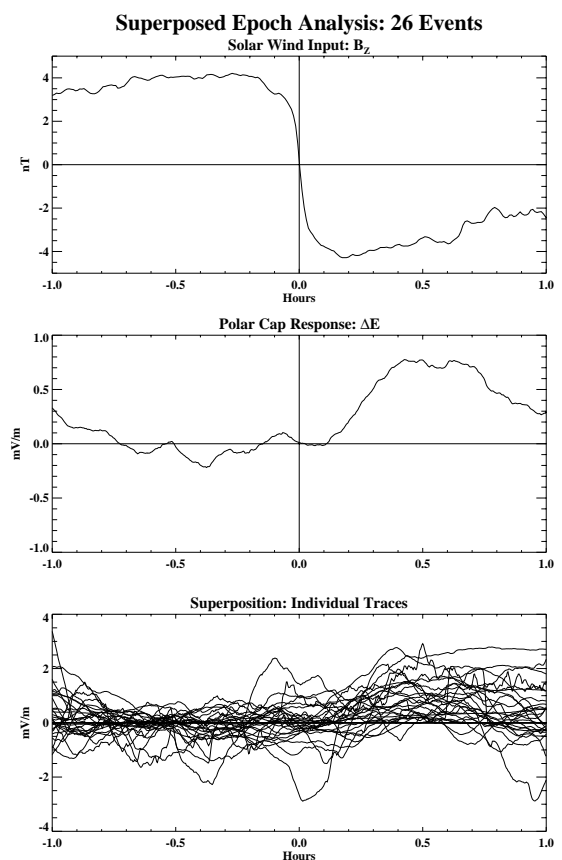

Figure 2: Superpositions of solar wind $B_{Z}$ and polar cap electric field data for 26 events. The third panel shows individual traces of the electric field data. (from Turner et al. [1998])

growth phase began just before POLAR detected an Efield change. The growth phase continued for about an hour and a half, and then substorm onset occurred at 0856 UT, as indicated by the dipolarization of the magnetic field observed by GOES 9. Further, the E-field state change seen by POLAR reversed after 2 hours and 51 minutes, which was the same duration that the interplanetary $B_{Z}$ was predominantly southward.

\section{Superposed Epoch Studies}

A superposition was conducted of all 26 events with the expectation that random changes would tend to average away, highlighting only consistent IMF-driven responses (Figure 2), and then a second superposition was conducted for the ten events for which GOES 9 was in the midnight sector in order to determine whether or not the field at geosynchronous orbit typically responds before the polar cap (Figure 3 ).

In the case of the electric field superposition, polar cap electric field data were aligned according to the solar wind arrival time at the magnetopause so that time zero coincided with the arrival of the solar wind change. Additionally, because only the change in the electric field was of interest, the signal mean before the arrival of the solar wind change was subtracted from each signal, so E-field measurements had a zero mean before the solar wind change. Finally, because there is no directional information in the spin-plane components alone [Turner et al., 1998], changes in the mean of the electric field were defined as positive (e.g., if the measured spin plane electric field decreased after the solar wind change, the entire signal for that event
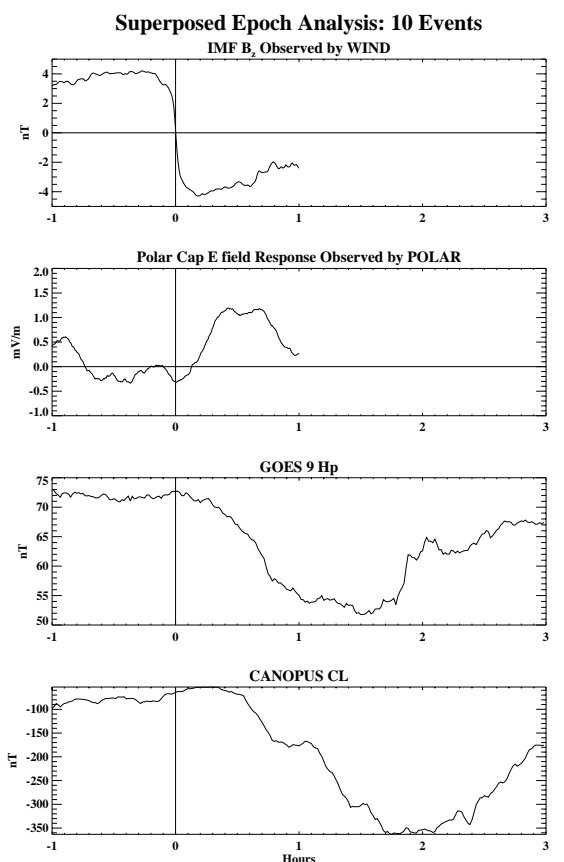

Figure 3: Superpositions of polar cap electric field data, geosynchronous magnetometer data and ground magnetometer data for ten events.

was multiplied by -1).

As shown in Figure 2, the electric field superposition for all events reveals a clear change in the mean polar cap electric field. Time zero is defined as the arrival time of the solar wind change at the magnetopause, and times are plotted in hours. The data show that the signal started to change by around 10 minutes and a change in the mean of about $0.5 \mathrm{mV} / \mathrm{m}$ occurred consistently by about 15 minutes after the solar wind changes reached the magnetosphere and after 30 minutes the change was on average about $0.8 \mathrm{mV} / \mathrm{m}$, with individual events as high as $2 \mathrm{mV} / \mathrm{m}$. Panel 3 shows all of the individual traces used in the study plotted together. From this figure it is evident that the change in the EFI signals shown in the superposition was the characteristic response for most events, and thus no single event overwhelmed the superposition.

Figure 3 shows the results of the ten-event superposition of electric and magnetic field data. Panel 1 shows the solar wind $B_{Z}$ as measured by the WIND spacecraft. Panel 2 shows the response measured by POLAR over the northern polar cap. Note that in this ten-event subset, it is more difficult to discern the exact response time due to fluctuations in the signal prior to time zero. This may simply be due to statistical fluctuations. Panel 3 shows the responses measured by the GOES 9 magnetometer. The superposition of GOES 9 data in this plot shows a very rapid response which is approximately the same time as that of the electric field data. Ground responses observed by the CANOPUS array are shown in panel 4. This superposition indicates a much longer response time, nearly 30 minutes. 


\section{Discussion}

The results presented here provide important information about how the magnetosphere begins to prepare for substorm energy unloading. They also speak to the speed at which information about a solar wind change can be propagated throughout the magnetosphere.

In the June 17 event, GOES 9 data showed a response to the IMF change before POLAR data responded, indicating that the electrodynamic coupling for the low-latitude magnetosphere was evidenced faster than over the polar cap. Prior work done on information propagation throughout the magnetosphere [e.g., Wilken et al., 1982 and Coroniti, 1985] suggests that wave propagation from the dayside magnetopause to the nightside magnetosphere near geosynchronous orbit probably travels as a fast mode compression wave. The fact that information about the IMF change reached GOES 9 before it reached POLAR implies that the signal propagation method into the polar cap region is a slower mode of transport, perhaps at Alfven speeds. This result is supported by the superposition of the GOES 9 data, which showed that for the ten events studied, GOES 9 observed a response in the magnetic field on about the same timescale as POLAR. This is also indicative of different propagation speeds and mechanisms.

The superposed epoch results indicate a consistent response in the polar cap electric field data. This 26-event superposition study showed that the mean electric field began to change, on average, about 10 minutes after a southward turning reached the magnetopause. After 15 minutes, the change was typically around $0.5 \mathrm{mV} / \mathrm{m}$, and it reached a maximum of about $0.8 \mathrm{mV} / \mathrm{m}$ after 30 minutes of southward IMF.

Turner et al. [1998] suggested that because the response time for the polar cap electric field did not appear to vary over the polar cap regions surveyed by POLAR that the electric field was likely imposed rapidly over a wide region. This result is consistent with work by Ridley et al. [1998], who found that the reconfiguration of the polar cap ionospheric convection patterns began in all regions of the polar cap nearly simultaneously - over a period of less than one minute. They concluded that the electric field applied across the cusp must control the entire dayside convection pattern, consistent with the description by Lockwood et al. [1990]. Additionally, the timescales in the Ridley et al. [1998] study are a few minutes shorter than the timescales derived from POLAR data for the highaltitude cap. This seems to suggest that once the electric field is imposed via the cusp, it affects the polar ionosphere, and then reaches the POLAR spacecraft (at 5-9 $R_{E}$ ) via an Alfven wave from the ionosphere. This is consistent with the aforementioned ionospheric convection studies and would explain the lack of a substantial delay seen by POLAR in the nightside cap relative to the dayside cap. At the same time, information appears to travel to geosynchronous orbit at a faster rate, possibly via a fast mode compression wave.

Acknowledgements. The authors would like to acknowledge R. P. Lepping and K. Ogilvie for providing WIND data and G. Rostoker for assistance in interpreting the CANOPUS magnetometer data. The CANOPUS instrument array was constructed and is operated by the Canadian Space Agency. Additionally, the authors would like to acknowledge the former P. R. Nelson. The work of H. Singer was supported in part by NASA Interagency Order No. S-67019-F. Work at CU/LASP was supported by grants from the NASA ISTP program.

\section{References}

Baker, D. N., T. I. Pulkkinen, V. Angelopoulos, W. Baumjohann, and R. L. McPherron, Neutral line model of substorms: past results and present view, J. Geophys. Res., 101, 12,975-13,010, 1996.

Coroniti, F. V., Explosive tail reconnection: the growth and expansion phases of magnetic substorms, J. Geophys. Res., 90, 7427-7447, 1985.

Cumnock, J. A., R. A. Heelis, and M. R. Hairston, Response of the ionospheric convection pattern to a rotation of the IMF on January 14, 1988, J. Geophys. Res., 97, 19,449$19,460,1992$.

Hairston, M. R. and R. A. Heelis, Response time of the polar ionospheric convection pattern to changes in the northsouth direction of the IMF, Geophys. Res. Lett., 22, 631634, 1995.

Harvey, P., F. S. Mozer, D. Pankow, J. Wygant, N. C. Maynard, H. Singer, W. Sullivan, P. B. Anderson, T. Aggson, A. Pedersen, C.-G. Fälthammar, and P. Tanskannen, The electric field instrument on the POLAR satellite, Space Sci. Rev., 71, 583-596, 1995.

Lockwood, M., S. W. H. Cowley, and M. P. Freeman, The excitation of plasma convection in the high-latitude ionosphere, J. Geophys. Res., 95, 7961-7972, 1990.

Ridley, A. J., G. Lu, C. R. Clauer, and V. O. Papitashvili, Ionospheric convection during nonsteady IMF conditions, J. Geophys. Res., 102, 14,563-14,579, 1997.

Ridley, A. J., G. Lu, C. R. Clauer, and V. O. Papitashvili, A statistical study of the ionospheric convection response to changing interplanetary magnetic field conditions using the assimilative mapping of ionospheric electrodynamics technique, J. Geophys. Res., 103, 4023, 1998.

Singer, H. and R. Wolf, Report of the working group on magnetotail/plasma sheet dynamics, Outstanding Questions in Geotail and Substorm Physics, Report of the GEM Workshop on the Physics of the Tail and Substorms, 51-58, 1992. Turner, N. E., D. N. Baker, T. I. Pulkkinen, H. J. Singer, F. Mozer, and R. P. Lepping, High altitude polar cap responses to southward turnings of the IMF, submitted to: J. Geophys. Res., 1998.

Wilken, B., C. K. Goertz, D. N. Baker, P. R. Higbie, and T. A. Fritz, The SSC on July 29, 1977 and its propagation within the magnetosphere, J. Geophys. Res., 87, 5901$5910,1982$.

Correspondence to: N. E. Turner (Fax: 1-303-492-6444, E mail: Niescja.Turner@lasp.colorado.edu) 